\title{
Analysis of reasons for extracting permanent teeth among Korean adults with oral diseases
}

\author{
Jae-Joon Byun ${ }^{1}$, Eun-Sun Jang ${ }^{1}$, Dae-Ryong Kong ${ }^{1}$, and Gyeong-Je Lee ${ }^{2 *}$ \\ ${ }^{1}$ Resident, Department of Prosthodontics, Collage of Dentistry, Chosun University, Gwangju, Republic of Korea \\ ${ }^{2}$ Associate Professorr, Department of Prosthodontics, Collage of Dentistry, Chosun University, Gwangju, Republic of Korea
}

This study aimed to analyze the main reasons for the extraction of permanent teeth among Koreans with oral diseases. The electronic medical record data for past 10 years was used in a target population comprising of 26,795 adults diagnosed with oral disease and scheduled to undergo permanent tooth extraction. The oral diseases were classified into periodontal disease, dental caries, impacted teeth, prosthodontic treatment, orthodontic treatment, tooth fracture, trauma, and others. The relationship between these diseases and permanent tooth extraction was analyzed. Permanent teeth were extracted due to periodontal disease (34.5\%), dental caries (26.6\%), and tooth impactions (22.3\%). Permanent teeth were extracted as the cause of dental caries (28.6\%) and periodontal disease (45.9\%) from patients in 26-35 and 46-55 years of age respectively. The mandibular first molars (17.2\%), mandibular second molars (16.0\%), maxillary first molars (14.7\%), and maxillary second molars (14.3\%) were extracted due to dental caries. The incidence of periodontal disease was highest in the mandibular central incisor $(72.6 \% ; p<0.05)$. These findings indicated that periodontal disease was the chief cause of extraction of permanent teeth among Korean adults.

Key Words: Dental caries; Periodontal disease; Permanent dentition; Tooth extraction

(c) This is an open-access article distributed under the terms of the Creative Commons Attribution Non-Commercial License (http://creativecommons.org/licenses/by-nc/4.0) which permits unrestricted noncommercial use, distribution, and reproduction in any medium, provided the original work is properly cited.

\section{Introduction}

경제성장과 함께 세계 인구 수가 증가하고 있으며 2050년 아 시아인의 인구는 2010 년과 비교하였을 때 $23 \%$ 증가할 것으로 예측하고 있다. 이런 인구변화에는 출산율 감소와 고령인구의 사망률 감소로 점차 인구 고령화로 이어지고 있다[1]. 연령이 증 가하면서 영구치 상실과 치아우식, 치주질환, 만성적인 구강건 조증이 빈번해지며, 이는 저작의 어려움과 의치사용 시 불편감 을 동반할 수 있다. 하지만, 이를 수용하고 인내하려는 경향으로 oal-health-related quality of life이 고령인구에서 낮게 평가되
고 있다[2].

영구치 발거 후 저작능력의 감소, 발음, 심미적인 문제 등을 야기할 수 있기 때문에 치료 방법 선택 시 신중해야 한다[3,4]. 구강질환에 의한 영구치 발거의 예방적 접근을 위해 이전 많은 연구들은 영구치 발거를 야기하는 구강질환을 치아우식, 치주 질환, 보철치료를 위한 발거, 교정치료를 위한 발거, 외상, 기타 원인들로 나누었고 치아우식과 치주질환이 세계적으로 공중구 강보건에 주요한 문제로 여기고 원인을 분석하기 위해 많은 노 력을 해왔다[2,5]. 캐나다의 연구에서는 치주질환이 $35.9 \%$ 과 치 아우식이 $28.9 \%$ 로 영구치 발거에 관여하였고 프랑스 연구에서

Received October 26, 2020; Revised [1] December 10, 2020; [2] December 23, 2020; [3] January 4, 2021; [4] January 12, 2021; Accepted January 16, 2021

*Corresponding author: Gyeong-Je Lee, Department of Prosthodontics, College of Dentistry, Chosun University, 303 Pilmun-daero, Dong-gu, Gwangju 61452, Republic of Korea.

Tel: +82-62-220-3820, Fax: +82-62-232-7776, E-mail: 1kj1998@chosun.ac.kr 
는 치아우식이 $49 \%$ 로 치주질환이 $32.4 \%$ 로 관여하였으며 가까 운 일본의 경우 치주질환이 $41.8 \%$, 치아우식이 $32.7 \%$ 로 발거와 관련있다는 결과를 얻었다[4,6,7]. 본 연구의 목적은 10 년간의 영구치 발거 자료를 토대로 한국인의 발거 원인에 대한 요인을 분석하는 것이다.

\section{Materials and Methods}

2010년 1월부터 2020년 4월까지 조선대학교 치과병원을 내 원한 환자들 중 전자의무기록(Electronic Medical Record)에 발치술 처방코드(U4412, U4413, U4414)로 등록된 영구치 발 거 환자 26,795 명을 추출하였고 주진단코드명을 기준으로 치주 질환, 우식, 보철치료, 교정치료, 매복치, 파절, 기타의 7 가지 해 당하는 환자 25,714 명을 선정하였으며, 근단주위농양 양성 신 생물, 치아의 외훕수, 치근낭, 함치성낭, 이외의 7 가지 항목으 로 분류가 어려운 환자 1,081 명을 제외하였다(Table 1). 남성 14,764 명, 여성 10,950 명으로 구성되었으며 연령은 18 세에서 최고 109 세로 총 60,376 개의 영구치가 발거되었다.

본 연구는 조선대학교 치과병원 기관생명윤리위원회(Institutional Review Board, IRB)의 승인을 받아 진행되었고(승인번 호: CUDHIRB 2003 001), 자료의 통계적 분석은 통계프로그램 Statistics for Windows, Version 23.0 (IBM Co., Armonk, NY, USA)을 이용하여 분석하였으며 성별, 연령별, 치아종류별 발거 원인을 교차분석의 Pearson Chi-square test를 사용하였다. 또 한, 영구치 발거에 미치는 영향을 분석하기 위해 회귀분석을 시 행하였으며 ANOVA test를 통해 적합성을 평가하였다.

구강질환 중 영구치 발거를 야기하는 원인을 전자의무기록상 의 진단코드명으로 우식, 치주질환, 매복치, 파절, 외상, 보철치 료 목적, 교정치료 목적, 기타로 분류하였다. 보철치료와 교정치 료를 위한 영구치 발거에 대한 명확한 진단 코드명이 존재하지 않기 때문에 본원 보철과와 교정과를 내원한 환자들 중 Table 1 에 해당하는 진단 코드명으로 분류하였다.

\section{Results}

지난 10 년간 25,713 명의 성인 환자가 구강질환으로 본원에 내원하여 영구치를 발거했으며, 통계적 분석 결과 성별과 연령 이 유의수준 $1 \%$ 하에서 유의함을 확인하였다. 구강질환 중 매 복치(28.0\%) 원인이 가장 많았으며 치주질환(26.3\%), 치아우 식(21.1\%)이 다음으로 주된 발거 요인이었다 $(p<0.05)$. 남성 14,763 명과 여성 10,950 명 중 치주질환에 의한 영구치 발거는 남성(29.3\%)이 여성(22.3\%)보다 발거 비율이 높았다. 반대로 치 아우식에 의한 영구치 발거는 여성(21.7\%)이 남성(20.6\%)보다 높게 나타났다. 매복치 발거는 여성(28.9\%)이 남성(27.3\%)보다 발거 비율이 높은 결과를 얻었다 $(p<0.05)$ (Table 2). 동일환자 가 다수의 치아를 발거한 경우를 고려하여 구강질환에 의해 발 거된 60,376개의 영구치 중 치주질환(33.5\%)에 의한 영구치 발 거가 가장 많았고 치아우식(26.6\%)이 다음으로 높게 나타났다 $(p<0.05)$ (Table 3). 성별 비교에서 치주질환은 남성(35.9\%) 이 여성(30.7\%)보다 높았고 치아우식의한 영구치 발거는 여성 (27.6\%)이 남성(25.7\%)보다 높게 나타났다. 매복치 발거는 여 성(23.0\%)이 남성 $(21.8 \%)$ 보다 높은 비율을 보였다 $(p<0.05)$ (Table 3).

연령별 구강질환에 의한 영구치 발거 분석결과 전체 연령대 에서 매복치(28.0\%)가 가장 높았고 치주질환(26.3\%), 치아우식 (21.1\%), 보철치료(14.7\%)순으로 나타났다. 25세 이하(23.6\%), 26-35세 이하(28.6\%)에서는 치주질환보다 치아우식에 따른 영 구치를 발거 경우가 많았고 36세 이상부터는 치주질환에 의한 영구치 발거가 치아우식에 의한 영구치 발거보다 높게 나타났 다. 46-55세(45.9\%)까지 연령이 증가할수록 치주질환에 의한 영구치 발거 경우가 증가했으며 그 이후 연령부터는 다시 감소 하는 결과를 얻었다. 매복치 발거는 25 세 이하(60.5\%)에서 가 장 높았고 연령이 증가할수록 발거 비율이 줄어들었다. 보철치 료를 위한 영구치 발거는 점점 연령이 증가할수록 영구치 발거 비율이 증가하였고 76 세 이상(42.5\%)에서 가장 높게 나타났다

Table 1. Classification criteria for extraction of permanent teeth

\begin{tabular}{ll}
\hline Reasons & \multicolumn{1}{c}{ Diagnosis } \\
\hline Perio & $\begin{array}{c}\text { Chronic periodontitis, Chronic simple periodontitis, Chorinc complex periodontitis, Unspecified chronic periodontitis, Acute } \\
\text { periodontitis, Tooth loss due to accidental extraction or localized periodontal disease } \\
\text { Dentin caries, Tooth caries, Cementitious caries, Unspecified dental caries, Caries with pulp exposure }\end{array}$ \\
$\begin{array}{l}\text { Caries } \\
\text { Impacted }\end{array}$ & $\begin{array}{l}\text { Impaction of maxillary 3rd molar, Impaction of mandibular 3rd molar. Supernumerary teeth } \\
\text { Prosth }\end{array}$ \\
Ortho & Root rest, Fracture and loss of dental prosthesis \\
Fracture & Crown fracture with pulp exposure, Crown-root fracture \\
Trauma & Toot intrusion and toot extrusion, tooth subluxation, luxation of tooth \\
Others & Apical abscess, Radicular cyst \\
\hline
\end{tabular}


Table 2. Patient number of permanent teeth extracted due to oral disease

\begin{tabular}{lccc}
\hline Reason & Male & Female & Total \\
\hline Perio & $4,330(29.3)$ & $2,442(22.3)$ & $6,772(26.3)$ \\
Caries & $3,036(20.6)$ & $2,381(21.7)$ & $5,417(21.1)$ \\
Impacted & $4,030(27.3)$ & $3,159(28.8)$ & $7,189(28.0)$ \\
Prosth & $1,938(13.1)$ & $1,845(16.8)$ & $5,417(21.1)$ \\
Ortho & $148(1.0)$ & $207(1.9)$ & $355(1.4)$ \\
Fracture & $548(3.7)$ & $272(2.5)$ & $820(3.2)$ \\
Trauma & $43(0.3)$ & $23(0.2)$ & $66(0.3)$ \\
Others & $690(4.7)$ & $621(5.7)$ & $1,311(5.1)$ \\
Total & $14,763(100.0)$ & $10,950(100.0)$ & $25,713(100.0)$
\end{tabular}

Values are presented as percentage (\%).

Table 3. Number of permanent teeth extracted due to oral disease

\begin{tabular}{lccc}
\hline Reason & Male & Female & Total \\
\hline Caries & $8,298(25.7)$ & $7,746(27.6)$ & $16,044(26.6)$ \\
Perio & $11,590(35.9)$ & $8,630(30.7)$ & $20,220(33.5)$ \\
Impacted & $7,033(21.8)$ & $6,459(23.0)$ & $13,492(22.3)$ \\
Prosth & $3,440(10.7)$ & $3,635(12.9)$ & $7,075(11.7)$ \\
Ortho & $258(0.8)$ & $348(1.2)$ & $606(1.0)$ \\
Fracture & $837(2.6)$ & $557(2.0)$ & $1,394(2.3)$ \\
Trauma & $92(0.3)$ & $44(0.2)$ & $136(0.2)$ \\
Others & $725(2.2)$ & $684(2.4)$ & $1,409(2.3)$ \\
Total & $32,273(100.0)$ & $28,103(100.0)$ & $60,376(100.0)$ \\
\hline
\end{tabular}

Values are presented as number (\%).

Table 4. Number of permanent teeth extracted by age

\begin{tabular}{|c|c|c|c|c|c|c|c|c|c|}
\hline \multirow{2}{*}{ Age } & \multicolumn{8}{|c|}{ Reason } & \multirow{2}{*}{ Total } \\
\hline & Caries & Perio & Impacted & Prosth & Ortho & Fracture & Trauma & Others & \\
\hline$<25$ & $1,647(23.6)$ & $518(7.4)$ & $4,222(60.5)$ & $167(2.4)$ & $272(3.9)$ & $45(0.6)$ & $9(0.1)$ & $98(1.4)$ & $6,978(100.0)$ \\
\hline $26-35$ & $1,065(28.6)$ & $402(10.8)$ & $1,780(47.8)$ & $246(6.6)$ & $58(1.6)$ & $56(1.5)$ & $5(0.1)$ & $114(3.1)$ & $3,726(100.0)$ \\
\hline $36-45$ & $614(23.5)$ & $859(32.9)$ & $569(21.8)$ & $295(11.3)$ & $18(0.7)$ & $86(3.3)$ & $19(0.7)$ & $149(5.7)$ & $2,609(100.0)$ \\
\hline $46-55$ & $706(19.4)$ & $1,672(45.9)$ & $307(8.4)$ & $514(14.1)$ & $6(0.2)$ & $204(5.6)$ & $15(0.4)$ & $221(6.1)$ & $3,645(100.0)$ \\
\hline $56-65$ & $652(17.1)$ & $1,694(44.3)$ & $201(5.3)$ & $771(20.2)$ & $1(0.0)$ & $239(6.3)$ & $12(0.3)$ & $250(6.5)$ & $3,820(100.0)$ \\
\hline $66-75$ & $479(15.8)$ & $1,088(35.8)$ & $87(2.9)$ & $984(32.4)$ & $1(0.0)$ & $133(4.4)$ & $6(0.2)$ & $260(8.6)$ & $3,038(100.0)$ \\
\hline $76<$ & $254(13.4)$ & $539(28.4)$ & $23(1.2)$ & $806(42.5)$ & $0(0.0)$ & $57(3.0)$ & $0(0.0)$ & $219(11.5)$ & $1,898(100.0)$ \\
\hline$p$-value & & & & & $<0.001^{*}$ & & & & \\
\hline
\end{tabular}

Values are presented as number (\%).

${ }^{*}$ Chi-square is used to evaluate the statistical significance between the age and reason groups.

(Table 4).

치아위치별 구강질환에 의한 영구치 발거 비율은 상하악 각 각 좌우측 구분없이 제3대구치를 포함해 8 개의 치아로 분류하 여 진행되었으며 상악(37,639개)은 하악(22,737개)보다 구강질 환에 의한 영구치가 발거가 많았다. 치아우식에 의해 상하악 제 3 대구치가 가장 많았으며 다음으로 하악 제1대구치(17.2\%), 하 악 제2대구치(16.0\%), 상악 제1대구치(14.7\%), 상악 제2대구
치(14.3\%)순으로 우식에 의해 발거되었다. 치주질환에 의한 영 구치 발거 중 하악 중절치(72.6\%), 하악 측절치(64.8\%)가 가장 빈번했으며 다음으로 상악 제2대구치(61.5\%), 상악 제1대구치 (57.0\%) 순서로 높은 결과를 얻었다(Table 5). 상하악 제3대구 치를 제외한 모든 영구치에서 치주질환이 치아우식보다 더 높 은 발거 비율을 보였다(Fig. 1).

2010년부터 2019년까지 본원을 내원한 환자 중 치아우식과 
Table 5. Number of the reasons for tooth extraction according to tooth type

\begin{tabular}{|c|c|c|c|c|c|c|c|c|}
\hline \multirow{2}{*}{ Tooth } & \multicolumn{8}{|c|}{ Reason } \\
\hline & Caries & Perio & Impacted & Prosth & Ortho & Fracture & Trauma & Others \\
\hline UM3 & $8,580(38.5)$ & $2,988(13.4)$ & $9,846(44.2)$ & $394(1.8)$ & $355(1.6)$ & $39(0.2)$ & $8(0.0)$ & $80(0.4)$ \\
\hline UM2 & $557(14.7)$ & $2,328(61.5)$ & $113(3.0)$ & $534(14.1)$ & $18(0.5)$ & $153(4.0)$ & $7(0.2)$ & $76(2.0)$ \\
\hline UM1 & $503(14.3)$ & $2,005(57.0)$ & $63(1.8)$ & $603(17.2)$ & $15(0.4)$ & $202(5.7)$ & $3(0.1)$ & $122(3.5)$ \\
\hline UPM2 & $229(12.3)$ & $847(45.5)$ & $39(2.1)$ & $511(27.5)$ & $10(0.5)$ & $133(7.2)$ & $4(0.2)$ & $87(4.7)$ \\
\hline UPM1 & 207 (11.7) & $872(49.1)$ & $16(0.9)$ & $473(26.6)$ & $13(0.7)$ & $109(6.1)$ & $7(0.4)$ & $78(4.4)$ \\
\hline UC & $171(11.2)$ & $649(42.4)$ & $12(0.8)$ & $609(39.8)$ & $2(0.1)$ & $15(1.0)$ & $1(0.1)$ & $72(4.7)$ \\
\hline ULI & $147(12.2)$ & $572(47.4)$ & $10(0.8)$ & $367(30.4)$ & $2(0.2)$ & $47(3.9)$ & $11(0.9)$ & $52(4.3)$ \\
\hline UCI & $154(9.2)$ & $825(49.3)$ & $24(1.4)$ & $414(24.7)$ & $12(0.7)$ & $134(8.0)$ & $31(1.9)$ & $79(4.7)$ \\
\hline LCI & $81(6.6)$ & $893(72.6)$ & $5(0.4)$ & $182(14.8)$ & $4(0.3)$ & $25(2.0)$ & $19(1.5)$ & $21(1.7)$ \\
\hline LLI & $61(7.6)$ & $518(64.8)$ & $1(0.1)$ & $170(21.3)$ & $1(0.1)$ & $10(1.3)$ & $4(0.5)$ & $35(4.4)$ \\
\hline LC & $111(10.1)$ & $552(50.1)$ & $1(0.1)$ & $352(31.9)$ & $2(0.2)$ & $16(1.5)$ & $13(1.2)$ & $55(5.0)$ \\
\hline LPM1 & $130(11.7)$ & $528(47.5)$ & $10(0.9)$ & $346(31.1)$ & $5(0.5)$ & $23(2.1)$ & $5(0.5)$ & $64(5.8)$ \\
\hline LPM2 & $158(11.7)$ & $581(42.9)$ & $32(2.4)$ & $436(32.2)$ & $5(0.4)$ & $58(4.3)$ & $3(0.2)$ & $82(6.1)$ \\
\hline LM1 & $573(17.2)$ & $1,475(44.30)$ & $93(2.8)$ & $749(22.5)$ & $24(0.7)$ & $185(5.6)$ & $8(0.2)$ & $223(6.7)$ \\
\hline LM2 & $682(16.0)$ & $2,311(54.1)$ & $297(7.0)$ & $556(13.0)$ & $8(0.2)$ & $222(5.2)$ & $6(0.1)$ & $191(4.5)$ \\
\hline LM3 & $3,700(38.8)$ & $2,276(23.9)$ & $2,930(30.7)$ & $379(4.0)$ & $130(1.4)$ & $23(0.2)$ & $6(0.1)$ & $92(1.0)$ \\
\hline Total & $16,044(26.6)$ & $20,220(33.5)$ & $13,492(22.3)$ & $7,075(11.7)$ & $606(1.0)$ & $1,394(2.3)$ & $136(0.2)$ & $1,409(2.3)$ \\
\hline$p$-value & \multicolumn{8}{|c|}{$<0.001^{*}$} \\
\hline
\end{tabular}

Values are presented as number (\%).

UM3, upper third molar; UM2, upper second molar; UM1, upper first molar; UPM2, upper second premolar; UPM1, upper first premolar; UC, upper canine; ULI, upper lateral incisor; UCI, upper central incisor; LCI, lower central incisor; LLI, lower lateral incisor; LC, lower canine; LPM1, lower first premolar; LPM2, lower second premolar; LM1, lower first molar; LM2, lower second molar; LM3, lower third molar.

${ }^{*}$ Chi-square is used to evaluate the statistical significance between the reason and tooth type.

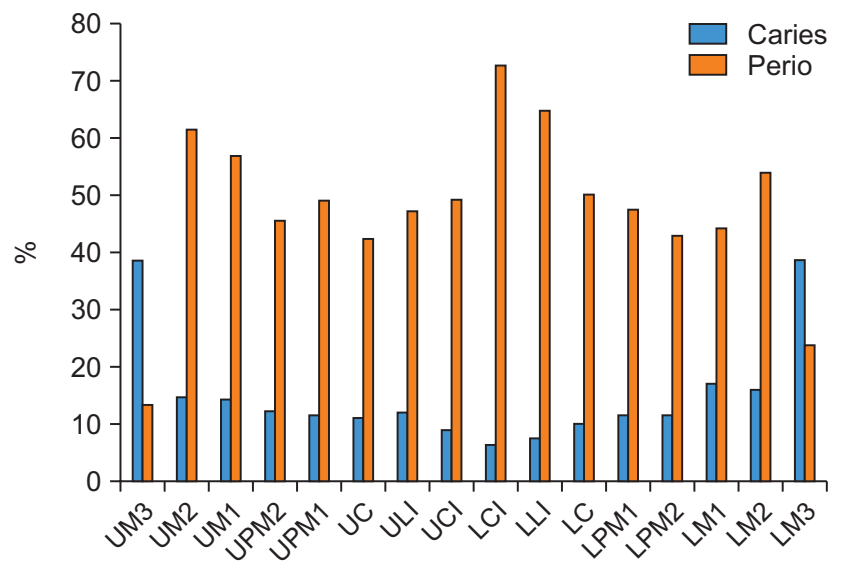

Fig. 1. Percentage of permanent tooth extraction by caries and periodontal disease according to tooth type. UM3, upper third molar; UM2, upper second molar; UM1, upper first molar; UPM2, upper second premolar; UPM1, upper first premolar; UC, upper canine; ULI, upper lateral incisor; UCI, upper central incisor; LCI, lower central incisor; LLI, lower lateral incisor; LC, lower canine; LPM1, lower first premolar; LPM2, lower second premolar; LM1, lower first molar; LM2, lower second molar; LM3, lower third molar.

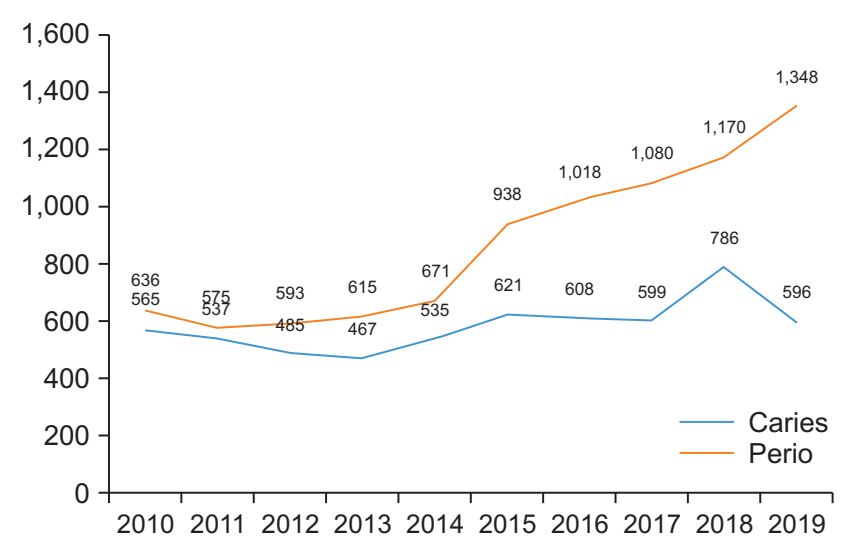

Fig. 2. Number of patients with extraction of permanent tooth due to dental caries and periodontal disease by year.

치주질환으로 영구치를 발거한 환자수를 비교했을 때 치아우식 은 10 년 전과 크게 변화가 없었고 치주질환에 의한 영구치 발 거는 2010년도와 비교해 보았을 대 현재 2배 이상 증가하였다

(Fig. 2). 


\section{Discussion}

많은 치과 의사들은 환자의 치료방법 결정 시 영구치를 보존 또는 발거할 지에 대한 고민을 한다. 그 이유는 구강 내 영구치 가 원활한 저작기능을 수행하기 위해서는 적어도 20 개의 영구 치가 잔존해 있어야 하며 자연치열과 비교하였을 때 가철성 국 소의치의 사용은 저작효율을 30-40\% 감소시키기 때문이다[8]. 영구치 상실의 문제점을 인식하고 전 세계적으로 영구치 발거 원인을 규명하기 위해 많은 연구들이 시행되었으며 여러 구강 질환 중 치아우식과 치주질환이 영구치 발거의 주된 원인이라 공통적으로 말하였다[5,8-10]. 하지만 두 질환 중 어느 것이 더 연관성이 있는지에 대해서는 여러 의견들로 나뉘며 본 연구 결 과와 마찬가지로 치주질환이 영구치 발거에 더 연관성이 있다 는 연구와 반대로 치아우식이 더 연관성이 있다는 의견도 있다 [4,6-8]. 또한, 이 두 가지 구강질환이 비슷한 비율로 영구치 발 거에 관여한다는 연구 결과도 있다[11].

본 연구 결과로 성별 영구치 발거 비율에서 남성이 여성보다 영구치 발거 비율이 높다는 통계적으로 유의할 만한 결과를 얻 었다. 그 이유로 여성이 안모에 대한 심미성을 더 고려하여 구강 위생관리에 신경을 쓰지만 남성은 치과진료를 위해 병원 내원 을 꺼려한다는 것이 이유라고 하였다[8,9]. 반대로 남성의 영구 치 발거 비율이 높은 연구들에서는 여성이 진료 시 발생하는 비 용을 고려하여 발거를 최종 치료방법으로 선택하는 경향이 높 았고 교정치료를 위한 영구치 발거 비율이 남성보다 높기 때문 이라고 설명하였다[3,5]. 구강질환별 비교에서는 남성은 치주질 환, 여성은 치아우식으로 영구치 발거 비율이 높았다. 이는 남성 의 흡연습관과 관련이 있다[5].

치아우식과 치주질환이 연령별 영구치 발거에 미치는 영향 에 대해 이전 연구들은 30세 이전까지는 치아우식이 발거의 주 된 원인이며 30세 이상부터는 치주질환에 의한 치아우식에 비 해 영구치 발거 비율이 높게 증가한다고 하였으며 이는 본 연구 결과와 동일하다 [5,12]. 치주질환의 증가는 노인연령에서 영양 공급의 부족, 행동력 감소, 면역력 감소가 원인이라고 하였으며 [3], 연령의 증가에도 치아우식이 지속되는 이유는 새로운 우식 병소의 발현보다는 기존 수복물과 보철물의 실패가 원인이라고 하였다[6].

치아별 발거 원인을 분석했을 때, 상악 영구치가 하악 영구치 보다 발거 비율이 높으며, 전치부는 수복과 근관치료를 위한 접 근성이 용이하고 심미적인 측면에서 발거를 미루기 때문에 구 치부보다 발거 비율이 낮다[3]. 또한 구치부는 저작기능과 관련 되어 있기 때문에 치아우식에 의한 영구치 발거가 전치부보다 높으며 하악 전치부는 구치부보다 치주질환에 의한 발거 비율 이 높다고 하였다[8,13]. 이는 본 연구 결과와 동일하지만 하악
대구치에서 치아우식에 의한 영구치 발거가 높고 제3대구치가 가장 적은 비율로 치주질환에 의해 발거 되었다는 이전 연구 결 과들과는 차이를 보였다[6,11].

구강질환에 의한 영구치 발거는 비가역적 치료로 발거 기준 을 갖고 치료방법을 선택해야 한다. 치주질환에 의한 영구치 발 거 기준은 3 도의 치아 동요도 혹은 치근이개부 침범, 부착치은 상실이 $5 \mathrm{~mm}$ 이상일 경우 발거를 결정하게 된다[11,14].

10 년간의 자료를 연도별로 분류하였을 때 치아우식과 치주 질환에 의한 영구치 발거 비율이 감소하지 않고 증가했다는 점 은 구강질환이 영구치 상실을 야기하는 것에 대한 인식과 교육 이 부족한 것으로 생각된다. 치주질환과 치아우식은 계속관리 가 필요한 만성질환이며 이를 관리할 수 있는 제도나 교육이 필 요하다[10]. 본 연구 결과가 예방적 치과 진료를 위한 적절한 구 강위생 관리 프로그램의 필요성과 치아우식, 치주질환이 발거 의 주된 원인임을 인지시킬 수 있는 자료로 사용될 수 있다. 이 는 치의학과 공중구강보건의 발전에 도움을 줄 것이며 영구치 발거와 관련된 빅데이터로 사용될 수 있을 것으로 기대한다. 다 만, 영구치 발거 원인이 구강질환에 국한되지 않고 환자의 교육 수준, 사회경제적 수준, 전신질환 등 여러 인자들에 영향을 받는 다는 점을 고려하여 향후 추가적인 연구가 필요할 것으로 생각 된다.

\section{Acknowledgements}

This study was supported by a research fund from Chosun University, 2019.

\section{Conflicts of Interest}

The authors declare that they have no competing interests.

\section{ORCID}

Jae-Joon Byun

https://orcid.org/0000-0003-4368-7415

Eun-Sun Jang

https://orcid.org/0000-0002-2596-2551

Dae-Ryong Kong

https://orcid.org/0000-0002-0723-1333

Gyeong-Je Lee

https://orcid.org/0000-0002-3545-2280 


\section{References}

1. Ezeh AC, Bongaarts J, Mberu B. Global population trends and policy options. Lancet 2012;380:142-148. doi: 10.1016/S0140-6736(12)60696-5.

2. Murray Thomson W. Epidemiology of oral health conditions in older people. Gerodontology 2014;31 Suppl 1:9-16. doi: 10.1111/ger.12085.

3. Sharif RA, Chaturvedi S, Suleman G, Elmahdi AE, Elagib MFA. Analysis of tooth extraction causes and patterns. Open Access Maced J Med Sci 2020;8:36-41. doi: 10.3889/ oamjms.2020.3784.

4. Aida J, Ando Y, Akhter R, Aoyama H, Masui M, Morita M. Reasons for permanent tooth extractions in Japan. J Epidemiol 2006;16:214-219. doi: 10.2188/jea.16.214.

5. Anand PS, Kuriakose S. Causes and patterns of loss of permanent teeth among patients attending a dental teaching institution in south India. J Contemp Dent Pract 2009;10:E057-64. doi: 10.5005/jcdp-10-5-58.

6. Murray H, Clarke M, Locker D, Kay EJ. Reasons for tooth extractions in dental practices in Ontario, Canada according to tooth type. Int Dent J 1997;47:3-8. doi: 10.1111/ j.1875-595x.1997.tb00670.x.

7. Cahen PM, Frank RM, Turlot JC. A survey of the reasons for dental extractions in France. J Dent Res 1985;64:10871093. doi: $10.1177 / 00220345850640081401$.
8. Ahmad FA, Alrashidi AM, Alajmi B, Alsharrad A. Causes and patterns of tooth loss among patients attending Riyadh Elm University hospital: a cross-sectional study. Oral Health Dent Sci 2019;3:1-5.

9. Haseeb M, Ali K, Munir MF. Causes of tooth extraction at a tertiary care centre in Pakistan. J Pak Med Assoc 2012;62:812-815.

10. Silva-Junior MF, Sousa ACC, Batista MJ, Sousa MDLR. Oral health condition and reasons for tooth extraction among an adult population (20-64 years old). Cien Saude Colet 2017;22:2693-2702. doi: 10.1590/141381232017228.22212015.

11. Ong G. Periodontal reasons for tooth loss in an Asian population. J Clin Periodontol 1996;23:307-309. doi: 10.1111/ j.1600-051x.1996.tb00550.x.

12. Chestnutt IG, Binnie VI, Taylor MM. Reasons for tooth extraction in Scotland. J Dent 2000;28:295-297. doi: 10.1016/s0300-5712(99)00069-x.

13. Da'ameh D. Reasons for permanent tooth extraction in the North of Afghanistan. J Dent 2006;34:48-51. doi: 10.1016/ j.jdent.2005.02.009.

14. Chrysanthakopoulos NA. Periodontal reasons for tooth extraction in a group of Greek army personnel. J Dent Res Dent Clin Dent Prospects 2011;5:55-60. doi: 10.5681/ joddd.2011.012. 